\title{
Inter-Religion Hate Speech in India: A Sociological Study on the Ambiguous Terminology of Secularism
}

\author{
Pooja Shankar \\ Second Year Student of National Academy for Legal Studies and Research, Hyderabad (NALSAR)
}

\begin{abstract}
Hate speech, among other things, is one of the most pressing issues in India today. The fact that our society and our nation are so culturally diverse may often lead to discrimination and cultural bias in one form or another. Thus, I decided to look into the matter in order to discover the probable reasons behind this display of hate speech, the mediums through which it is often exhibited, and why people react differently to hate speech presented in different forms and degrees, e.g., why citizens would throw a riot for a political figure displaying some form of hate speech, as opposed to a young schoolboy. I have conducted a survey on inter-religion hate speech in India, with questions ranging from the religion the survey takers follow, to the level of hate speech they have either engaged in or been subjected to, to their faith in the Indian Judicial system to develop appropriate laws governing hate speech.My survey ranges all over India for reasons which are explained in my analysis, and the target audience of this survey rests in the educated youth of the country. For this reason, I have sent emails to various colleges in India, and received a total of approximately 100 responses. It was not particularly anabundant response, but it was a sufficient basis for me to infer the necessary conclusions upon. I have analysed the results of my survey and managed to compare and link them with various sociological aspects of life, supported by relevant data and hypothesesconcocted by various sociologists and philosophers such as, Jacques Derrida, AshisNandy, UpendraBaxi, etc.This paper further delves into the connection between hate speech and the law. It discusses the probable reasons as to why there is no dedicated and codified statute prohibiting hate speech in India, and it also discourses the difference between the definitions of secularism in the West and in the East, and how these definitions may impact and influence the hate speech laws of those respective countries.
\end{abstract}

\section{What is Inter-Religion Hate Speech in India?}

Inter-religion hate speech has primarily been understood in India as speech intended to promote hatred or violence between India's religious communities. It refers to that medium of communication through which personal bias of people following certain religions is expressed against people of other religions. It openly articulates the individual abhorrence of one community or one individual of that community against another. It is used on a relatively common basis and tends to be expressed not only in private, but on a public forum. ${ }^{1}$

The contemporary problem with hate speech in India is the fact that is stands as an exceedingly colloquial term. The definition, though vaguely understood as what I have written above, is not viewed as the same throughout the country among different people and different sections of society. For this reason, I have given a relatively standard definition for inter-religion hate speech in my survey in order to provide a customary basis for students to answer the questions. However, the definition includes my understanding of hate speech in layman terms that carries a certain level of ambiguity, rather than a concrete demarcation, in order to leave some room for interpretation by the survey takers and to assess the extent of the dissimilarity between the different interpretations for the purpose of drawing conclusions as to the probable reasons behind this variance in elucidations. Thus, in my survey, I have defined inter-religion hate speech as "any speech or hurtful remark that expresses the speaker's disinclination towards any particular religious community."

\section{Elaboration of Survey Questions}

Question 1: What stream are you studying in?

This question was basically aimed at ascertaining which students studying in which streams are more actively involved and concerned with the issue of hate speech. The fact that $88 \%$ of the answerers study in the medium of law suggests that law students are generally better informed on such topics and have more of an opinion, as they would have perhaps learnt something or studied about it.

\footnotetext{
${ }^{1}$ Michel Rosenfeld,Hate Speech in Constitutional Jurisprudence: A Comparative Analysis, Cardozo Law Review, Vol. 1, 2002-2003.
} 


\section{Question 2: What is your gender?}

Here, one may be able to draw conclusions in later questions depending upon the sexuality of an individual, and thus determine whether a particular gender has been subject to hate speech relatively more than the other. This will help us determine whether gender has a role to play in inter-religion hate speech. About $46 \%$ of the people who answered this survey were male, the rest $54 \%$ were female.

\section{Question 3: What religion do you follow?}

The point of this question was to create a basis of analysis for the survey in order to ascertain which religions indulged in or were affected by hate speech the most, and thus develop a comparative analysis. Under this, about $89 \%$ of answerers were Hindus, $7 \%$ were Muslims and $4 \%$ were Christians. From this, one may infer that the population of Muslims and Christians is, in general, much smaller than that of Hindus, with respect to colleges in India. Is it because Muslims and Christians are less entitled to a college-level education in comparison with Hindus? Does India take its majority and home religion so seriously that it impacts any other religion's ability to seek admission into a good college? Is the reason for this enormous difference in answers and college students of certain religions, discrimination possibly arising out of hate speech?

\section{Question 4: Do you believe that hate speech is a serious problem?}

The point of this question was to determine whether people understand what hate speech really is and to find out if they believe it is a problem in our society. $85 \%$ of survey takers said it is a serious problem, $13 \%$ said it is not and $2 \%$ did not even attempt the question. From this, one may infer that the $13 \%$ who do not see hate speech as a problem, probably haven't faced it and may have possibly indulged in it, themselves. Thinking they were right to indulge in it, they may not believe that it is a problem, but a mere display of personal feelings. The $2 \%$ who did not attempt the question are perhaps not aware of what hate speech is. Given that these are college students, evidently, $2 \%$ of India's "educated" population isn't aware of basic and prominent societal issues, which really tells us either that the education system has failed in bringing fundamental awareness among its students, or that the students simply do not care.

\section{Question 5: Have you ever indulged in hate speech towards any particular religion?}

The purpose of this question was to ascertain the average number of people that actually engage in hate speech against other religions and compare it to the number of people who have been victims of hate speech, and thus determine whether victims incidentally become the perpetrators, perhaps in retaliation, or whether people both engage in and are victims simply because that is the way society works. For this question, $22 \%$ of survey takers took said yes, and $88 \%$ said no. This implies that most of these answerers do not actually indulge in hate speech. But, perhaps they have been victims of it?

\section{Question 6: If yes, towards which religion?}

This question sought to discover the average most frequent and regular subjects of hate speech. It was seen that out of the people who indulge in hate speech, 36\% of them do it towards Hindus, 36\% of them do it towards Christians and a whopping $82 \%$ of them do it towards Muslims. Clearly, one can see that there are overlapping numbers here. This implies that the survey takers indulging in hate speech may not necessarily target only one religion, but multiple. Also, one may establish that Muslims face the greatest level of hate speech. Hindus and Christians are also subject to a considerable level of hate speech, but it is indeed more prominently seen among Muslims. Is it because of the misconstrued generalization made by people that "Muslims are terrorists"? Is the Muslim hate speech by Hindus mainly due to their pre-existing rivalry dating back to perhaps the dawn of the Mughal Empire, progressing its way into the India-Pakistan split postindependence? Or is it just some personal hatred by an individual against another individual who just happened to be Muslim, thus universalizing all Muslims to be "bad". Muslims have been regarded as outcasts in Indian society more than any other religion for the longest time. Is there a need to change this? Yes. Will the common people in Indian society agree? No.

\section{Question 7: Was it a true reflection of your beliefs or was it merely humourous?}

This question seeks to establish whether the people who engage in hate speech do it out of spite for that religion, whether it has just come up as a joke, or whether they've disguised their spite for that religion in the form of a joke. What caught my interest here is that only 22 out of 100 people said they indulged in hate speech, but 44 people answered question 7 . This could either mean that the people who failed to admit they do not indulge in hate speech do not actually understand what it entails, despite the definition provided be me, or that they are simply in denial. They may feel that joking about a religion does 
not necessarily fall within the scope of hate speech, but what they fail to realize is, any negative comment towards any community, class or religion does indeed fall within the scope of hate speech, no matter what package it comes in. Out of these 44 people, $9 \%$ said their hate speech was reflection of their beliefs alone, $63 \%$ claimed it was merely humour, and $28 \%$ said that it was both. Noting that the largest percentage of people claimed it was for humour, perhaps the above conclusion that people who humourously insult other religions do not truly consider it "hate speech" can be maintained.

\section{Question 8: Have you ever been a victim of hate speech?}

This question onwards focuses on the victims of hate speech and seeks to determine the average percentage of people from educated, moderately wealthy backgrounds facing hate speech. One may say that hate speech is extremely common among the lower and lower middle class who may not receive enough education to understand that all religions are equally important and deserve an equivalent amount of respect. From this survey, the results showed that $37 \%$ of people have been victims of hate speech, and $63 \%$ have not. This shows that people from educated, well-to-do backgrounds possibly face a lower level of hate speech than those coming from uneducated, unaware and less economically stable backgrounds. The $37 \%$ of people who do face this hate speech, however, possibly face it due to the personalfeelings of and grudges held by the offenders.However, it is not necessary that hate speech is mainly seen among the lower classes. We see hate speech coming from wealthy and competitive politicians in an effort to gain more votes and support from people of similar beliefs during elections and whatnot.

Another element of this question is the fact that a large number of Hindus stated that they have never victims of hate speech, whereas all the Muslims who took this survey stated that they have been victims of hate speech. This shows that Muslims tend to be more victimized than any other religion in terms of hate speech.

\section{Question 9: How often have you felt victimized by hate speech?}

This question was meant to determine the frequency of hate speech faced by these victims. It would help determine that hate speech was simply a passing comment, or a never-ending tremor they face due to their religious background. It was seen that about $9 \%$ face it daily, $11 \%$ face it quite often, $60 \%$ face it occasionally, and $20 \%$ rarely face it. These results suggest that most of these victims face this hate speech occasionally, rather than on a daily basis or often or rarely. This implies that hate speech among students is not particularly a regular occurrence, but does happen from time to time in their lives. Out of the Muslims who took this survey, about 12\% claimed they face hate speech rarely, $28 \%$ said they face it occasionally, $43 \%$ said they face it quite often, and $17 \%$ of them said they face it daily. This shows that Muslims are indeed comparatively faced with a greater average level of hate speech, and most of it is faced quite often. We thus establish a link between question 6 and questions $8 \& 9$. We see the largest percentage of indulgers in hate speech making such comments against people of Islamic origin. And we see that all the Muslims taking this survey have been victimized by hate speech, and face it more often than people of other religions.

\section{Question 10: Has this hate speech ever been accompanied by any form of discrimination or social exclusion?}

The purpose of this question was to discover whether the hate speech seen eventually leads to or is seen with discrimination of any kind. The results produced that $30 \%$ of the time, it is, and $70 \%$ of the time, it is not. Looking at this, we observe that most of the time, hate speech is seen to be merely an insulting comment without any subsequent or accompanied discrimination. But, it is accompanied by discrimination in some form or the other at times, which implies that hate speech may not necessarily be a mere comment, but a comment that could influence a particular aspect of an individual's life, and has certainly done so for that $30 \%$.

\section{Question 11: Where have you faced this hate speech?}

This question sought to determine the areas in which these students face hate speech most in order to ascertain whether it was something they faced in their youth (which would imply that they have faced it throughout their life while growing up) and is possibly something they have been facing recently within the walls of their educational forums, or something they face outside their educational environments (which would imply they are subject to hate speech anywhere outside the comfort of their own homes). $68 \%$ of survey takers claiming to have faced hate speech said they faced it in school or college, and $32 \%$ said they face it outside school and college. From these results, one can say that people have been subject to hate speech in school and college the most. Knowing that children are being subject to such insulting comments in their place of learning would clearly make one ponder how much these abusive remarks are affecting their lives within the confines of their educational spacing. 


\section{Question 12: Has this hate speech ever curbed your performance in school/college?}

This question was meant to determine just how much the hate speech these students have faced have managed to impact their studies, co- and extra-curricular activities in school and college. It establishes whether these remarks have affected them so much to the extent of restraining their success in school and college. This restrained success may be due to mental abuse arising out of such hate speech, thus curtailing their academic and extra-curricular performance, or simply because limiting the performance of these students. 19\% of survey takers said it curbed their performance in either school or college, and $81 \%$ said that it did no such thing. Thus, one may infer that most students are not impacted by hate speech to the extent of letting it impact their studies. Most of them seem to brush off the comments and live life normally. However, there are those who have felt their performance in school and college could have been better had they not been so mentally instigated.

\section{Question 13: Do you believe that hate speech has ever restricted your chances in political events, such as elections, in your school or college?}

This question sought to ascertain the level of impact of hate speech on the chances of students in political events in their colleges. This could include simple things ranging from House Captain to elections for Student Body President. 50\% of the people subjected to hate speech claimed it did restrict their chances in school and college political events, and the rest $50 \%$ claimed it did no such thing. From this, we observe that though a large number of students have not felt impacted in this circumstance, an equally significant number of students have felt degraded and cheated when it came to these school/college political events. Hate speech may indeed impact their stance and chances in such events. What was interesting in this survey was that all Muslim survey takers claimed they believed that hate speech did restrict their chances in these events, but not all of the other survey takers of other religions felt so. This brings us back to an earlier point made where Muslims tend to receive a greater level of discrimination as compared to followers of other religions, and certainly face heavier consequences than them. This is clearly seen in the results of this question.

Question 14: Do you believe that freedom of speech justifies hate speech?

This was an interesting question that was meant to determine whether people secretly believe that hate speech is quite natural and ought to be acceptable. $14 \%$ said it is justified by freedom of speech, and $86 \%$ said it is not. One thingthat grasped my attention in this question was the fact that the $14 \%$ of people who believe that it is justified comprise completely of all those people who have indulged in hate speech. This may show that people who pass these abusive remarks clearly believe that it is acceptable and that they are completely justified in whatever they say, if not because of Article 19 of the Constitution, because they believe they are right.

\section{Question 15: If no, do you believe hate speech should be restricted by law?}

The purpose of this question was to look into the personal opinions of the people answering this survey, and allowing them to utilize whatever knowledge they have on the subject of hate speech, its repercussions, its advantages, etc. and develop an appropriate answer. The fact that $81 \%$ of survey takers believe that it should be restricted by law shows that this percentage believes it is indeed a problematic conduct and needs to be regulated by a legal body. The rest $19 \%$ who claim that it does not require such governance either do not view hate speech as too much of a problem, or perhaps they are expressing a submissive lack of faith in our legal system to effectively restrict it.

\section{Question 16: Do you think such restriction could ever be properly enforced?}

This is a continuation of question 15. It seeks to determine the faith of the student population in our legal and judicial system. The results were very close. $49 \%$ of the survey takers believe that it can be properly enforced, and $51 \%$ believe that it cannot. This shows that there is a very balanced expectation of the public out of India's legal system. Personally, I do not believe that it can be properly enforced for reasons such as the fact that there is no concrete definition of hate speech. It is an extremely broad concept with several varying aspects within the basic definition itself that cannot be concretized to the extent of efficient enforcement. Apart from carrying a vague demarcation, hate speech would be quite difficult to monitor. Perhaps, an issue of this level of commonality is still too young to be meritoriously governed and made formally punishable. Will the legal system develop separate laws for virtual hate speech via the internet? Will it develop proper mediums of control? Will it monitor people and consistently invoke justice with regards to any form of hate speech? These are things that the judicial system will ultimately find problematic to comply with.

\section{Sociological Analysis}

Throughout the analysis of this survey, I have managed to draw links between the results of the surveyand various sociological concepts and prevailing legal issues. The first connect I established is the fact 
that hate speech is an extremely colloquial term. We have the Indian interpretation of hate speech, and we have the Western interpretation of hate speech. Both interpretations are different, but are nevertheless, based upon the same principle. Both interpretations characterize hate speech as biased remarks against a particular class or section of society. For the West, it could involve diversity with respect to different religions, or it could involve the concept of White v. Black. The White Supremists regard themselves as the "highest level of purity" or the ultimate level of power. And the blacks are regarded as the lower classes, tainted with a treatment difference due to their supposedly undesirable colour. In the west, hate speech usually exists between these two sections of society. But, in India, we see that hate speech is often both caste and religion-based.

The castes are a sort of hierarchy, similar to that of the Western interpretation of white supremacy. Here, the Brahmins replace the whites, and form the "highest level of purity".Different religions have grown to almost despise each other, which is where these abusive comments come into the picture. How have these religions become so, one might ask? Referring to UpendraBaxi's article, ${ }^{2}$ we find that when the British invaded India, it saw India's caste system and diversity of religions, and blatantly labeled them as intolerant towards each other. Hence, they tried to impose secularism on the Indian society. But, this was problematic, because when you impose secularism, you assume that all cultures and religions are intolerant. Hence, the British were unable to make a proper distinction. Baxi's problem was that the British colonizers came to India and imposed their legal systems as they believed all sections of society were intolerant to each other.Gandhi had disagreed and said that the problem with the British was that they were looking at Indian society from the surface. Folk culture was nothing like their interpretation, as every culture would be living together harmoniously. In fact, before Ashoka (the Hindu King), no one truly understood the distinction between one culture and another. But, people now understand the distinction, ${ }^{3}$ which is why my survey requires the mandatory "What religion do you follow?" question. And, when the British arrived and imposed secularism, enforcing this alien doctrine to the Indian people that only private practice of religion is allowed and that they must acknowledge the existence of other religions, it essentially made the people feel stronger about their own religions and created this sense of defensiveness amongst them. Because they began to feel more defensive about their religion, they became more enriched in their practice of caste and religion, which is what the British were seeking to abolish. The fact that the British were imposing this secularism made it seem as though the state was enforcing a sort of tolerance of other religions, which the people did not appreciate. This essentially displays how different religions have grown to despise each other even though they may publicly depict a sense of fake tolerance, which shows how hate speech may have come about. The people are perhaps so fatigued by this oppressive force dictating that they are obligated to be tolerant of other cultures and religions, that the egg containing their ethnic frustration eventually cracks, and they act out in abusive and insulting ways whether in the form of violence, or mere verbal assault. Here, we see how this intolerance of other religions (mainly Hinduism) to people following Islam has accelerated over the years. The ethnic frustration has surfaced and grudges possibly dating back to the very moment the Mughal Empire was born, and progressing to the date of independence and the establishment of the India-Pakistan border, thus explaining how Muslims tend to be the most targeted section of society, as we observed from the results of question 6. This leads to the creation of hate speech in India, and creates a clear dissimilarity as to how it may have come about here, as opposed to the west.

This discussion on hate speech essentially leads to arguments regarding secularism. We establish a distinction between secularism in India and secularism in the West. Thus, there are essentially two definitions of secularism. The first would be religious tolerance coming only from devaluation of religion in public and from freeing of politics from religion. The second definition would include being equally respectful or disrespectful of all religions. India claims to follow the second. However, we have only been able to discover through time that India truthfully only follows the first definition. India refers to secularism as a neutral attitude of the state, local government or public services in matters relating to religion. It is non-religious, rather than anti-religious. ${ }^{4}$ However, we observe that religious tolerance seen by the state is not necessarily religious tolerance seen by society. The state may develop this so-called faith in secularism only for the purpose of politics. Indian politicians today are claimed to have a superior political consciousness when they are not believers of religion. ${ }^{5}$ However, we clearly observe the use of religion to the advantage of these so-called secular politicians when it comes to gaining the support of the politically active and religion common sections of society they attempt to

\footnotetext{
2 UPENDRABAXI, Conflicting Conceptions of Legal Cultures and Conflict of Legal Cultures, Journal of The Indian Law Institute, Vol. 33, April-June, No. 2.

${ }^{3}$ UPENDRABAXI, Supra n.2.

${ }^{4}$ Justice R.A. Jahagirdar, Secularism in India: The Inconclusive Debate, available at: http://iheu.org/content/secularism-india, last accessed October 14, 2013.

5 AshisNANDY, An Anti-Secularist Manifesto, India International Centre Quarterly, Vol. 22, No. 1, 1995.
} 
appeal to. In the west, secularism is described as something opposed to religion. It is something which has nothing to do with God or with anything super-natural or transcendental. ${ }^{6}$

Another link one might establish is between question 13 and the paradigm of form and substance. When we look at the instance of a school, where a small boy may pass a harmless remark against his Muslim classmate, we often tend to shrug it off and move on. But, why is it that when a politician makes the very same remark, riots break out and chaos erupts? This is where we bring in the concept of form and substance, which has been established by Jacques Derrida. ${ }^{7}$ He brings in his theory of deconstruction and explains that the only understanding any philosophical text is linked with the form in which it is put forth. Hence, it is impossible to understand any text, any concept, and any theory without knowing its form. For example, when a teacher is teaching us a certain concept, we learn about that concept only to the extent of that method of teaching used. If a different method is used, we will understand differently. For this reason, we see that justice is only as good as the form of law put out, which is another explanation as to the effectiveness of the current provisions governing what it thinks can be classified as hate speech to a certain extent.

Looking at Derrida's theory of form and substance, we observe that a politician's words are taken to mean something completely different from that of an innocent schoolboy due the form through which the comments are being passed. The form of a politician will obviously lead to a different interpretation of that of a schoolboy. Society may not take a young boy's opinion so seriously, but it will surely consider what a politician has to say and may be influenced to some extent depending upon the wisely chosen words of these politicians coupled with their own interpretations. The substance that a form taking the image of a politician conveys will be more valued and taken more seriously than that of young child.

Applying this to question 13, we see that people subjected to hate speech may sometimes be impacted by it to the extent that it affects their position in political elections and events. Here, we observe that politics have a created a role for religion to play in society. Suppose there is a community entrenched in its cultural and traditional beliefs of caste hierarchy and religious dominance, and a certain person in an election (whether in school/college or outside) makes a statement showing his support for the existing hierarchy, he is likely to gain the votes of the many people who believe in this social pyramid. This defensiveness of religion among politicians, seen after British rule, was a result of their imposition of secularism and banning of proclamation of religious views on a public forum, which essentially brought religion into politics through a back door. Thus, people often use their religion to their advantage in politics, which may be observed from the results of question $13 .^{8}$ So, it may be said that politicians tend to use hate speech to their advantage, and use it to gain support or votes during elections. We may also apply this form and substance theory to the question regarding the humourous nature of hate speech (question 7). When people make such remarks in a humourous fashion, it is less likely to be taken seriously. Perhaps the targeted religion may also view it as a joke. But, if the tone of voice and the facial expressions of the passer of the comment are altered to imply he is being serious, even if he is using the same words as the humourous comment, people will naturally think that he believes what he is saying, and the targeted religion will indeed feel victimized and hurt by his words. We can draw another link between this question to sociology. The people who said they had indulged in hate speech both for humour and as a reflection of true beliefs, had perhaps made their remarks disguised as a joke, but was actually a reflection of their beliefs. This is where the concept of residuaries and derivations come into the picture. Residuaries are the sentiments most frequently present in the human consciousness and derivations are the intellectual systems with which people camouflage their passions. For Vilfredo Pareto, opinions are merely rationalization of basic residues. ${ }^{9}$

\section{Hate Speech and the Law}

According to AshisNandy, we make a choice between the western and the Indian mode of secularism, and we lean towards the West. ${ }^{10}$ Using it as a basis of hate speech, do the laws of different countries on hate speech depend upon their interpretations of secularism? In the West, we observe that secularism refers to the fact that the exercise of legitimate state power takes place in secular terms, the fact that all citizens can freely exercise their religious freedom and worship one God, another God or no God at all, and the fact that the Churches and the State are neatly separated. It is secularism in this sense which is captured by the French term

\footnotetext{
${ }^{6}$ BandhuIshanandVempeny, Western Secularism and Religion-Centered Indian Secularism, available $a t$ :http://formationguj.blogspot.in/2011/11/western-secularism-and-religion-centred.html, last accessed October 14, 2013.

${ }^{7}$ JACQUES DERRIDA, Force of Law: The "Mystical Foundation of Authority" in Drucilla Cornell, Michel Rosenfeld and David Gray Carlson (eds.) Deconstruction and the Possibility of Justice, New York: Routledge. ${ }^{8}$ ASHISNANDY, An Anti-Secularist Manifesto, India International Centre Quarterly, Vol. 22, No. 1, (1995).

${ }^{9}$ Michael MCLure, Pareto, Economics and Society, Vol. 1, Taylor and Francis Group,p.12, (2001).

${ }^{10}$ AsHIS, Supra n.5.
} 
laicité, the Italian laicità, the Spanish laicidad and which in English must be somewhat tortuously translated as "religious neutrality" and is captured by the two clauses of the First Amendment of the US Constitution. We could call secularism in this first meaning "political secularism". 11

In the US, we observe that hate speech is not illegal, as it is actually classified as free speech. They believe that actions speak louder than words, and that the only way to deal effectively with hate speech is to create laws and policies that discourage bad behaviour, but do not punish bad beliefs, or in other words, to create laws and policies that do not attempt to define hate speech as hate crimes. ${ }^{12}$

Since the end of World War II, many European countries have witnessed a propagation of hate speech legislation designed to curb stimulation to racial and religious hatred. Though originally intended to guard against the kind of xenophobic and anti-Semitic propaganda that gave rise to the Holocaust, today, national hate speech laws have increasingly been invoked to criminalize speech that is merely deemed insulting to one's race, ethnicity, religion, or nationality. The crusade to demarcate the bounds of free expression has its roots in three instruments of international law which include; the European Convention on Human Rights (ECHR),the International Convention on the Elimination of All Forms of Religious Discrimination (CERD), and the International Covenant on Civil and Political Rights (ICCPR). Article 10 of the ECHR grants the freedom of expression to all, but the exercise of this right is subject to certain restrictions, including, "for the protection of the reputation and rights of others." Further, Article 4(a) of the CERD obligates signatories to make "all dissemination of ideas based on racial superiority or hatred" a punishable offense, while Article 20 of the ICCPR requires outlawing "any advocacy of national, racial, or religious hatred that constitutes incitement to discrimination, hostility, or violence."Given the unclear standards on which much of Europe's hate speech laws are based, given that there is not even a universally agreed upon definition for what constitutes hate speech, it is little wonder that such legislation has ensnared speech it was likely never meant to punish. There is a fine and highly subjective line between speech that is considered rude and that which is considered insulting and worthy of criminal prosecution, and effectively defining this line is something that governments are ill-suited to determine. $^{13}$

Thus, we see that the western interpretation of secularism is so distinct in itself, that it forces various nations with the western hemisphere to view it as something different, thus developing different laws. The US clearly views secularism as something that is more of a choice, rather than a state-imposed obligation. For that reason, it does not criminalize hate speech, as it is considered to come within the bounds of 'freedom of speech'. However countries of the European Union believe that secularism is not only a state-imposed societal obligation, but they believe that freedom of speech is required to be limited to the extent of avoiding any speech that could merely harm the sentiments of a particular religious community.

As I have mentioned earlier, India interprets secularism as a neutral attitude of the state, local government or public services in matters relating to religion, and is non-religious, rather than anti-religious. ${ }^{14}$ However, we observe that religious tolerance seen by the state is not necessarily religious tolerance seen by society, and the state is aware of this. Perhaps this is why India refuses to criminalise hate speech specifically, but penalizes certain actions that may or may not be interpreted to fall within the definition of hate speech.

Section 153A of the Indian Penal Code criminalises the promotion of "enmity between different groups on grounds of religion, race, place of birth, residence, language etc," or "doing acts prejudicial to maintenance of harmony" through "words, either spoken or written, or by signs or by visible representations or otherwise". 15

Section 153B forbids "imputations and assertions prejudicial to national-integration". It outlaws the use of "words either spoken or written, signs, or by visible representations or otherwise". ${ }^{16}$

Article 25(1) of the Constitution of India states, "Subject to public order, morality and health and to the other provisions of this Part, all persons are equally entitled to freedom of conscience and the right freely to profess, practice and propagate religion".Article 19 gives its citizens the right to freedom of speech and expression subject to "reasonable restrictions" for preserving "public order, decency or morality". Article 28 prohibits any religious instruction in any educational institution exclusively sustained out of state funds. Article 51A(h)

\footnotetext{
${ }^{11}$ Alessandro Ferrara, Three Meanings of Secularism, available at: http://www.resetdoc.org/story/00000000773, last accessed December 22, 2013.

${ }^{12}$ Students in Action, Debating Hate Speech, available at:

http://www.americanbar.org/groups/public_education/initiatives_awards/students_in_action/debate hate.html, last accessed October 14, 2013

${ }^{13}$ The Legal Project, European Hate Speech Laws, available at: http://www.legal-project.org/issues/europeanhate-speech-laws, last accessed December 22, 2013.

14 Justice R.A. Jahagirdar, Supra n.4.

${ }^{15}$ Sec. 153A, Indian Penal Code, 1860.

${ }^{16}$ Sec. 153B, Indian Penal Code, 1860.
} 
prescribes that every national has the duty to develop the scientific temper, humanism and the spirit of inquiry and reform. ${ }^{17}$

These sections are intended to prevent perhaps a lighter, relatively general understanding of the simplest form of hate speech, but fail to prohibit "hate speech" in particular. No section in the IPC is dedicated to prevent hate speech alone, but it does look to prevent similar crimes that may be brought within the scope of hate speech. Thus, there is no particular law governing hate speech in its most fundamental state, which is why questions 15 and 16 are brought into the survey. These questions sought to determine whether the public feels there can be a properly established definition and codified mode of regulation, or not. Evidently, they feel as though the present understanding of hate speech is too ambiguous to be effectively codified. There are several elucidations of this one term, and without being legally defined, there is no way to codify such a law.

Personally, I do not believe that hate speech can be properly enforced for reasons such as the fact that there is no concrete definition of hate speech. It is an extremely broad concept with several varying aspects within the basic definition itself that cannot be concretized to the extent of efficient enforcement. Apart from carrying a vague demarcation, hate speech would be quite difficult to monitor. Perhaps, an issue of this level of commonality is still too young to be meritoriously governed and made formally punishable. Will the legal system develop separate laws for virtual hate speech via the internet? Will it develop proper mediums of control? Will it monitor people and consistently invoke justice with regards to any form of hate speech, even if very minimal damage has actually been caused? These are the things that the judicial system will ultimately find problematic to comply with.

\section{Conclusion}

Conducting this survey, I have managed to gather much information regarding the personal opinions of students and their individual experiences with respect to hate speech. It managed to produce results that I was able to effectively analyze and link with numerous sociological concepts developed by theorists such as Derrida, Nandy, and Baxi. Further, it has provided a basis for me to investigate upon the ideology of secularism and hate speech law in the West versus India.

Through this paper, I have established four main deductions that one ought to familiarize oneself with. First, most victims of hate speech happen to be those of Islamic origin. Second, hate speech is an extremely colloquial term that is defined differently, yet based upon the same principle, in different countries. Third, secularism is a utopian state of mind that will never be completely accepted and followed by the people of Indian society, possibly owing to the gravity of pre-existing rivalry between religions, cultures and classes. The society is too entrenched in its separate values and beliefs that it refuses to consider the existence of any others and the possibility that the other beliefs may be equally valid. In fact, secularism is a concept that will never completely and universally be accepted by people in any society in any country, owing to the versatility of it interpretations.And finally, one may see that the Western and Eastern interpretation of secularism and hate speech does indeed impact the state's laws governing the same.

These deductions may not be entirely true, but they are what I managed to gather based upon my field analysis and I imagine that they would be accurate to the extent of my research, coupled with my sociological interpretations and connections.

${ }^{17}$ Constitution of India, 1950. 